\title{
Estudo Estratégico da Cadeia Produtiva da Indústria Cerâmica no Estado de São Paulo: Parte III - Indústrias de Colorifícios, Sanitários e Cerâmica Técnica - Isoladores
}

\author{
Marsis Cabral Junior ${ }^{a *}$, Paulo Brito Moreira de Azevedo ${ }^{b}$, Gláucia Cuchierato ${ }^{c}$, \\ José Francisco Marciano Motta ${ }^{\mathrm{d}}$ \\ ${ }^{a}$ Laboratório de Recursos Hídricos e Avaliação Geoambiental - LABGEO/Centro de Tecnologias Geoambientais / Instituto de \\ Pesquisas Tecnológicas do Estado de São Paulo - IPT \\ ${ }^{b}$ Coordenadoria de Planejamento e Negócios / Instituto de Pesquisas Tecnológicas do Estado de São Paulo - IPT \\ c GeoAnsata Projetos e Serviços em Geologia, São Paulo - SP, Brasil \\ ${ }^{d}$ Consultor - Bolsista Fapesp, São Paulo - SP, Brasil \\ *e-mail:marsis@ipt.br
}

\begin{abstract}
RESUMO
Este trabalho deriva de estudo de maior abrangência dirigido à elaboração de um diagnóstico técnico-econômico da indústria cerâmica no estado de São Paulo, com vistas a subsidiar ações de governo que garantam o abastecimento sustentável de matérias-primas minerais a este setor da economia. Entre as cerâmicas tradicionais foram priorizados os segmentos industriais de maior relevância econômica no Estado e com consumo significativo de bens minerais, a saber: Cerâmica Vermelha, Revestimentos, Louça Sanitária, Louça e Porcelana - Mesa, Utilitários e Decoração, Colorifícios (Fritas, Esmaltes e Corantes) e Isoladores Elétricos (Cerâmica Técnica). Nesse contexto, as avaliações desses segmentos e a análise estratégica efetuadas buscaram estabelecer um arcabouço de informações, bem como sugestões de iniciativas para o fortalecimento do setor produtivo, que poderão auxiliar a formulação de políticas para modernização e aprimoramento do sistema de suprimento mineral ao parque cerâmico paulista.

Os principais resultados desse estudo estão sendo apresentados em uma série de quatro artigos. Os dois primeiros, já publicados, abordaram a contextualização e fatos motivadores do estudo, breve histórico e características gerais da indústria cerâmica no Estado, sendo tratados os segmentos de cerâmica vermelha e revestimentos. Neste terceiro artigo são analisadas as indústrias de colorifícios, sanitários e de isoladores elétricos. O segmento de louça e porcelana - mesa, utilitários e decoração, e a análise estratégica da cadeia produtiva mínero-cerâmica farão parte do quarto artigo.
\end{abstract}

Palavras-Chave: cerâmica; matérias-primas, indústria; mineração; tecnologia

\section{INTRODUÇÃO}

Este trabalho decorre de estudo desenvolvido pelo Instituto de Pesquisas Tecnológicas do Estado de São Paulo (IPT, 2018) e financiado pela Subsecretaria de Mineração da Secretaria de Energia e Mineração - SEM do Estado de São Paulo ${ }^{1}$, que envolveu a elaboração de um diagnóstico técnico-econômico da indústria cerâmica no Estado de São Paulo, com a finalidade de coletar subsídios que permitam orientar ações de governo que garantam o abastecimento sustentável de matérias-primas minerais necessárias a este setor da economia, a curto, médio e longo prazo.

\footnotetext{
${ }^{1}$ Com a reforma da estrutura administrativa do governo paulista em 2019, as atribuições da Subsecretaria de Mineração foram integradas a Coordenadoria de Petróleo, Gás e Mineração dentro da Secretaria Estadual de Infraestrutura e Meio Ambiente- SIMA.
}

Contido nesse escopo geral, o desenvolvimento do estudo contemplou as seguintes metas:

a) caracterização qualitativa da estrutura de mercado e empresarial do elo central da cadeia produtiva cerâmica, isto é, do segmento de manufatura cerâmica, abrangendo os principais segmentos de manufatura cerâmica intensivos em consumo de minerais industriais, a saber: Cerâmica Vermelha, Revestimentos, Louça Sanitária, Louça e Porcelana de Mesa e Decorativa, Isoladores Elétricos e Colorifícios (fritas, esmaltes e corantes);

b) projeções de consumo de bens minerais: estimativa de crescimento do parque cerâmico e da demanda derivada de insumos minerais, circunstanciada em três cenários de crescimento (pessimista, neutro e otimista); e 
c) avaliação estratégica do setor cerâmico: indicações conclusivas sobre os principais fatores que interferem na competitividade da indústria cerâmica paulista e sugestão de diretrizes e ações para o aprimoramento competitivo, mormente relacionadas à demanda de bens minerais.

Os principais resultados desse estudo estão sendo apresentados em uma série de quatro artigos. Os dois primeiros, já publicados (Cabral Junior et al., 2019a; b), abordaram a contextualização e fatos motivadores do estudo, breve histórico e características gerais da indústria cerâmica no Estado, sendo tratados os segmentos de cerâmica vermelha e revestimentos. Neste terceiro artigo são analisadas as indústrias de colorifícios, sanitários e de isoladores elétricos, buscando-se caracterizar a estrutura produtiva e empresarial, o sistema de suprimento mineral e as matérias-primas consumidas. O segmento de louça e porcelana (mesa, utilitários e decoração) e a análise estratégica da cadeia produtiva mínero-cerâmica farão parte do quarto artigo.

\section{A INDÚSTRIA DE COLORIFÍCIOS}

O principal produto fabricado pelos colorifícios são as fritas cerâmicas, que são compostos vítreos, insolúveis em água, obtidos pela fusão seguida de resfriamento rápido de misturas controladas de matérias-primas. As fritas são utilizadas nas formulações de esmaltes e engobes, insumos essenciais para as indústrias cerâmicas, utilizadas no recobrimento superficial das peças, sendo consumidos em mais larga escala pelo segmento de revestimentos e, secundariamente, pelas indústrias de louças sanitárias e de mesa, isoladores elétricos, entre outras.

Até uma década atrás esse segmento estava organizado em uma associação denominada Abracolor - Associação Brasileira de Colorifícios, mas foi desativada e não há disponibilização sistematizada de informações do setor. Sendo o segmento de revestimento responsável por grande parte do consumo dos insumos fabricados nos colorifícios, as estimativas de produção desse segmento e, consequentemente, da sua demanda de matérias-primas minerais, foram balizadas pelo desempenho da indústria de placas cerâmica, aferidas adicionalmente com entrevistas com produtores, fornecedores e especialistas do setor.

Além das fritas, outros produtos fornecidos pelos colorifícios são compostos, esmaltes, engobes, pastas serigráficas, granilhas e corantes. Todos esses insumos são elaborados a partir da mistura das fritas pré-produzidas com outras matérias-primas naturais e sintéticas adquiridas pelos colorifícios, e atendem às necessidades específicas das etapas do processo de fabricação das peças cerâmicas em que são introduzidos, assim como às características desejadas no produto final. Os esmaltes, como o recobrimento mais externo, são aplicados à superfície dos corpos cerâmicos e, após queima, formam uma camada vítrea, delgada e contínua. As finalidades básicas desses vidrados são aprimorar a estética, tornar o produto impermeável e melhorar a resistência à abrasão.
Ilustrando a interação entre o esmalte e o corpo de uma peça cerâmica, a Figura 1 apresenta uma seção transversal típica de um placa vista ao microscópio eletrônico de varredura, na qual estão identificadas as camadas produzidas à partir de insumos fornecidos pelos colorifícios - engobe, esmalte e decorações - bem como suas respectivas espessuras. O suporte ou biscoito, como também é conhecido, constitui a parte basal, mais espessa da placa cerâmica e que recebe as sucessivas coberturas do engobe e do esmalte, incluindo a decoração.

Pioneiramente, as empresas líderes foram a Colorobia (Itália), Degussa (Alemanha), Ferro Enamel e Johson \& Mathey (EUA). A partir dos anos 2000, uma ação agressiva do setor produtivo, articulada a centros de pesquisa e com importante suporte governamental, alçou os colorifícios espanhóis, concentrados no cluster cerâmico de Castellon, no domínio do mercado internacional (Cabral Junior et al., 2010a).

\subsection{Contexto Brasileiro}

Seguindo as características do mercado internacional, a produção de colorifícios no país é relativamente concentrada. Na década de 1990, apenas cinco fornecedores respondiam por $64 \%$ das vendas. Já nos anos 2000, dez empresas respondiam por $80 \%$ da oferta, o que prevalece até os dias atuais. No entanto, nesse período houve movimentações, com paralizações, saída e entrada de novas empresas no mercado nacional. A Tabela 1 relaciona as empresas que conta com unidades no país, discriminando-se a origem do capital, localização e especialização produtiva.

Em 1999, o faturamento no Brasil do segmento foi de US\$ 140 milhões com a produção de $72.000 \mathrm{t}$ de fritas, $2.400 \mathrm{t}$ de corantes, $4.000 \mathrm{t}$ de granilha, $6.600 \mathrm{t}$ de produtos para serigrafia e $145.000 \mathrm{t}$ de compostos (ABCeram, 2001). Fortemente alavancado pelo expressivo crescimento da indústria de revestimento, já em 2008, a produção dos colorifícios alcançou cerca de $500 \mathrm{mil}$ toneladas de produtos, correspondendo a um faturamento de R\$ 1,26 bilhão (Coelho e Boschi, 2009). Atualmente, estima-se que o nível de atividade do segmento situa-se praticamente nesse mesmo patamar, haja vista que a produção embora tenha crescido até 2015 , começou

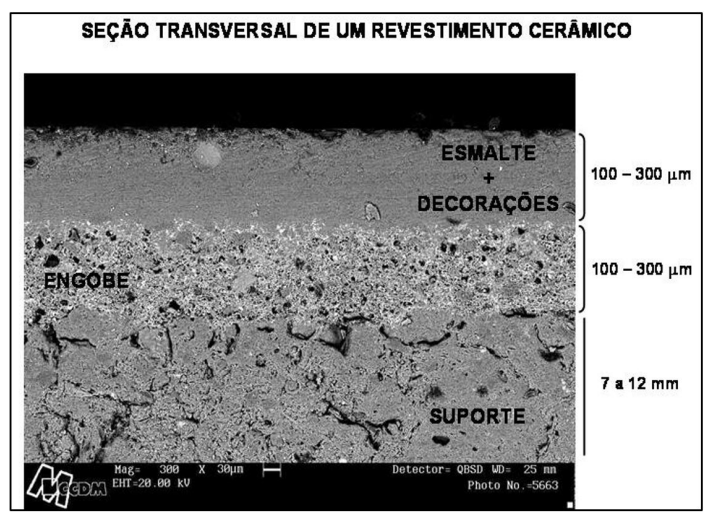

Fonte: Boschi (2005)

Figura 1- Seção transversal de uma placa de revestimento cerâmico. 
Tabela 1 - Colorifícios e empresas de processamento de produtos de acabamento de peças cerâmicas.

\begin{tabular}{|c|c|c|c|c|}
\hline & COLORIFÍCIO & ORIGEM & LOCAL & ATIVIDADE \\
\hline 1 & $\begin{array}{l}\text { ESMALTEC- } \\
\text { TERRAR I. C. }\end{array}$ & Brasil & Rio Claro- SP & $\begin{array}{l}\text { Fabricação de fritas, moagem de fritas e matérias-primas, } \\
\text { formulação e mistura de compostos }\end{array}$ \\
\hline 2 & $\begin{array}{l}\text { COLOROBBIA } \\
\text { DO BRASIL }\end{array}$ & Itália & Itatiba - SP & $\begin{array}{l}\text { Fabricação de fritas, moagem de fritas e matérias primas, } \\
\text { formulação e mistura de compostos }\end{array}$ \\
\hline 3 & $\begin{array}{l}\text { ESMALGLASS } \\
\text { DO BRASIL }\end{array}$ & Espanha & $\begin{array}{l}\text { Morro da Fumaça - SC } \\
\text { Rio Claro- SP }\end{array}$ & $\begin{array}{l}\text { Fabricação de fritas, moagem de fritas e matérias primas, } \\
\text { formulação e mistura de compostos } \\
\text { Formulação e mistura de compostos }\end{array}$ \\
\hline 4 & TORRECID & Espanha & Içara - SC & $\begin{array}{l}\text { Fabricação de fritas, moagem de fritas e matérias primas, } \\
\text { formulação e mistura de compostos }\end{array}$ \\
\hline & & & Araras- SP & Formulação e mistura de compostos \\
\hline 5 & $\begin{array}{l}\text { FERRO ENAMEL } \\
\text { DO BRASIL }\end{array}$ & EUA & Americana- SP & $\begin{array}{l}\text { Fabricação de fritas, moagem de fritas e matérias primas, } \\
\text { formulação e mistura de compostos. } \\
\text { Em agosto de } 2019 \text {, a empresa comunicou que encerrará } \\
\text { a produção de fritas e compostos no Brasil, continuando a } \\
\text { comercializar produtos para decoração de vidros, chapas } \\
\text { metálicas, tintas digitais, entre outros; adicionalmente } \\
\text { alguns produtos para compostos cerâmicos serão fornecidos } \\
\text { a partir de fábricas fora do Brasil. }\end{array}$ \\
\hline 6 & COLORTEC & Brasil & Cordeirópolis - SP & $\begin{array}{l}\text { Fabricação de Fritas, moagem de fritas e matérias primas, } \\
\text { formulação e mistura de compostos }\end{array}$ \\
\hline 7 & $\begin{array}{l}\text { SMALTICERAM } \\
\text { DO BRASIL }\end{array}$ & s.i.c. & $\begin{array}{l}\text { Içara - SC } \\
\text { Rio Claro- SP }\end{array}$ & $\begin{array}{l}\text { Fabricação de fritas, moagem de fritas e matérias primas, } \\
\text { formulação e mistura de compostos } \\
\text { Formulação e mistura de compostos }\end{array}$ \\
\hline 8 & VIDRADOS BS & Brasil & Ipeuna - SP & $\begin{array}{l}\text { Fabricação de fritas, moagem de fritas e matérias primas, } \\
\text { formulação e mistura de compostos }\end{array}$ \\
\hline 9 & COLORMINAS & Brasil & Rio Claro- SP & $\begin{array}{l}\text { Fabricação de fritas, moagem de fritas e matérias primas, } \\
\text { formulação e mistura de compostos } \\
\text { Formulação e mistura de compostos (fábrica de fritas e } \\
\text { moagem atualmente desativadas) }\end{array}$ \\
\hline 10 & NOVACOLOR & Brasil & Içara - SC & $\begin{array}{l}\text { Fabricação de fritas, moagem de fritas e matérias primas, } \\
\text { formulação e mistura de compostos }\end{array}$ \\
\hline & & & Cordeirópolis- SP & Formulação e mistura de compostos \\
\hline 11 & ROCHAFORTE & Brasil & N. S. Socorro- SE & $\begin{array}{l}\text { Fabricação de fritas, moagem de fritas e matérias primas, } \\
\text { formulação e mistura de compostos }\end{array}$ \\
\hline 12 & TERRACOR & Brasil & Cordeirópolis- SP & Produção de corantes \\
\hline 13 & $\begin{array}{l}\text { ICRA PROD. P/ } \\
\text { CERÂMICA }\end{array}$ & Brasil & Mogi Guaçu - SP & Produção de aditivos, corantes, tintas \\
\hline 14 & $\begin{array}{l}\text { IND. JACERU } \\
\text { DUREX S.A. }\end{array}$ & Brasil & São Paulo - SP & Fabricação de fritas cerâmicas \\
\hline 15 & $\begin{array}{l}\text { R I S I PRO D. } \\
\text { CERÂMICOS }\end{array}$ & Brasil & Mogi Guaçu - SP & Comercialização de matérias-primas, esmaltes, tintas \\
\hline 16 & ÔMEGA & Brasil & Cocal do Sul - SC & Comércio de corantes cerâmicos \\
\hline 17 & GRANTEC & Brasil & Estiva Gerbi- SP. & s.i.c. \\
\hline 18 & $\begin{array}{l}\text { EUROGLAZE IND. } \\
\text { COM. }\end{array}$ & Brasil & $\begin{array}{l}\text { Cosmópolis - SP } \\
\text { Paralisada }\end{array}$ & $\begin{array}{l}\text { Fabricação de fritas, moagem de fritas e matérias primas, } \\
\text { formulação e mistura de compostos }\end{array}$ \\
\hline 19 & $\begin{array}{l}\text { ENDEKA } \\
\text { CERAMICA }\end{array}$ & Inglaterra & $\begin{array}{l}\text { Estiva Gerbi- SP } \\
\text { Paralisada }\end{array}$ & $\begin{array}{l}\text { Fabricação de fritas, moagem de fritas e matérias primas, } \\
\text { formulação e mistura de compostos }\end{array}$ \\
\hline 20 & $\begin{array}{l}\text { FRITTA SL PROD. } \\
\text { P/CER. }\end{array}$ & Espanha & $\begin{array}{l}\text { Cordeirópolis- SP } \\
\text { Paralisada }\end{array}$ & $\begin{array}{l}\text { Fabricação de fritas, moagem de fritas e matérias primas, } \\
\text { formulação e mistura de compostos }\end{array}$ \\
\hline 21 & $\begin{array}{l}\text { TAUS PROD. } \\
\text { CERAMICOS }\end{array}$ & s.i.c. & $\begin{array}{l}\text { Sta Gertrudes - SP } \\
\text { Paralisada }\end{array}$ & $\begin{array}{l}\text { Fabricação de Fritas, moagem de fritas e matérias primas, } \\
\text { formulação e mistura de compostos }\end{array}$ \\
\hline 22 & $\begin{array}{l}\text { VIDRESDO BRASIL } \\
\text { LTDA. }\end{array}$ & s.i.c. & $\begin{array}{l}\text { Sta Gertrudes - SP } \\
\text { Paralisada }\end{array}$ & $\begin{array}{l}\text { Fabricação de Fritas, moagem de fritas e matérias primas, } \\
\text { formulação e mistura de compostos }\end{array}$ \\
\hline \multicolumn{5}{|c|}{$\begin{array}{l}\text { Obs.: (1) Indústrias relacionadas de acordo como o volume de produção; (2) na coluna Colorifício, as assinaladas } \\
\text { em negrito são as maiores unidades e as em itálico são unidades paralisadas; (3) na coluna "Local", as assinaladas } \\
\text { em negrito correspondem às unidades em cidades paulistas; (4) sic - sem informação complementar. }\end{array}$} \\
\hline
\end{tabular}


a decair a partir desse ano, acompanhando a queda na produção de revestimentos.

Após um longo período de expansão, com as principais empresas sediando-se no sul do país em função do cluster pioneiro de revestimentos em Santa Catarina, ocorreu uma descentralização das operações dos colorifícios, com instalações em São Paulo e na região Nordeste.

O mercado recessivo nos últimos anos e elevada capacidade de produção instalada acirraram a competição no segmento, diminuindo margens de lucro e causando paralisações ou fechamento de unidades. Por sua vez, as empresas não têm montado novos fornos de fusão, mas apenas estruturas de mistura de compostos. Assim, a maior parte dos novos empreendimentos que se instalou no polo de Santa Gerturdes só conta com operações de processamento de misturas, acompanhada de equipe de desenvolvimento e assistência técnica. É o caso da Esmalglass, Torrecid, Smaltceram, Colorminas e Novacolor. Ressalta-se que a Colorminas, que era um das empresas líderes brasileira e possuía fábricas em Rio Claro (SP) e Nossa Senhora do Socorro (ES), foi reestruturada e, atualmente, dispõe de produção de fritas apenas em Santa Catarina.

A produção brasileira dos colorifícios (Figura 2) foi estimada com base na produção de revestimentos cerâmicos. Houve crescimento até 2014, com certa estabilização em 2015 e decréscimo em 2016 e 2017, quando foram produzidas cerca de 550 mil t de material. ${ }^{2}$

A segmentação do mercado pode ser observada na Figura 3, depreendendo-se que os compostos ${ }^{3}$ e esmaltes são os principais insumos comercializados.

Considerando que a importação dos insumos fornecidos pelos colorifícios é insignificante, pode-se inferir que a indústria brasileira de colorifícios está entre as maiores do mundo, pois acompanha a produção da indústria de revestimento, onde o país ocupa o terceiro lugar, atrás de China e Índia.

A Figura 4 apresenta de forma esquemática o processo de fabricação da frita cerâmica, que corresponde ao principal produto sintetizado pelos colorifícios. Os demais insumos fornecidos pelos colorifícios para as indústrias cerâmicas são constituídos, basicamente, de misturas das fritas com outras matérias-primas minerais (naturais e sintéticas) adquiridas de outros fornecedores.

Em termos de configuração, as plantas industriais são compostas de três segmentos: estrutura de armazenamento e mistura de matérias-primas minerais, o setor de fusão (fornos com queima de gás natural enriquecido com oxigênio) e estrutura de resfriamento e secagem.

Os colorifícios consomem uma grande variedade de matérias-primas naturais e sintéticas, requerendo, mais do que os outros segmentos cerâmicos, elevada pureza e

${ }^{2}$ A estimativa de produção foi efetuada a partir da produção de revestimentos, considerando uma relação média de consumo de $700 \mathrm{~g}$ de cobertura (engobe e esmalte) por $\mathrm{m}^{2}$ de placa cerâmica.

${ }^{3}$ Compostos referem-se a misturas de frita com matérias-primas naturais - feldspato, quartzo e caulim com propriedades rigidamente controladas.

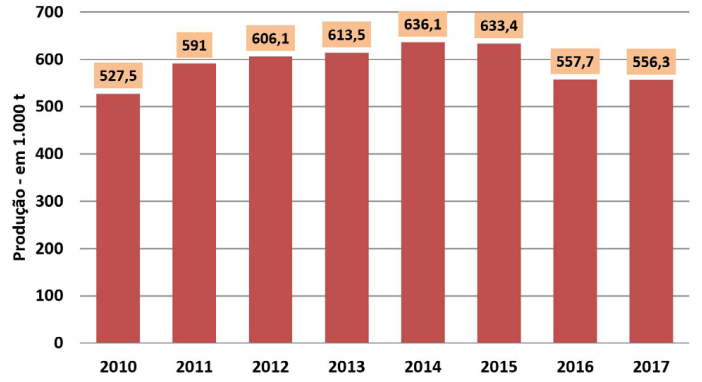

Fonte: elaborado pelos autores a partir de informações da produção de revestimentos computada em Cabral Junior et al. (2019b).

Figura 2 - Produção brasileira da indústria de colorifícios período 2010-2017.

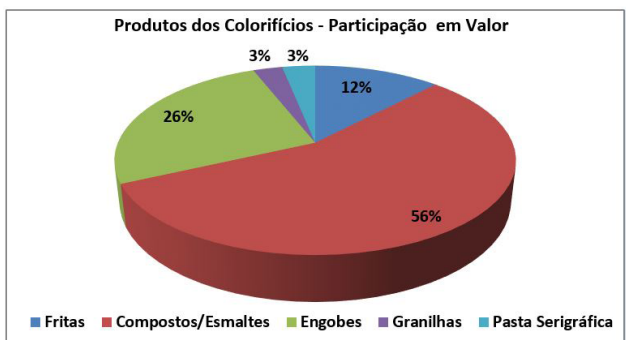

Fritas Compostos/Esmaltes Engobes Granilhas Masta Serigráfica

Produtos dos Colorifícios - Participação em Volume

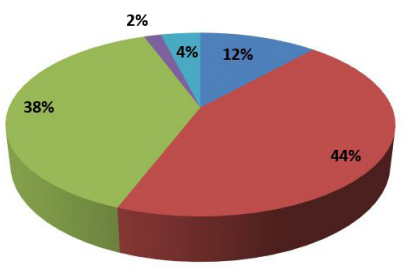

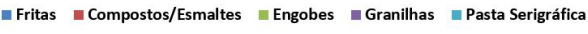

Fonte: elaborado a partir de atualização de Cabral Junior et al. (2010a). Figura 3 - Produtos dos colorifícios: segmentação do mercado brasileiro.

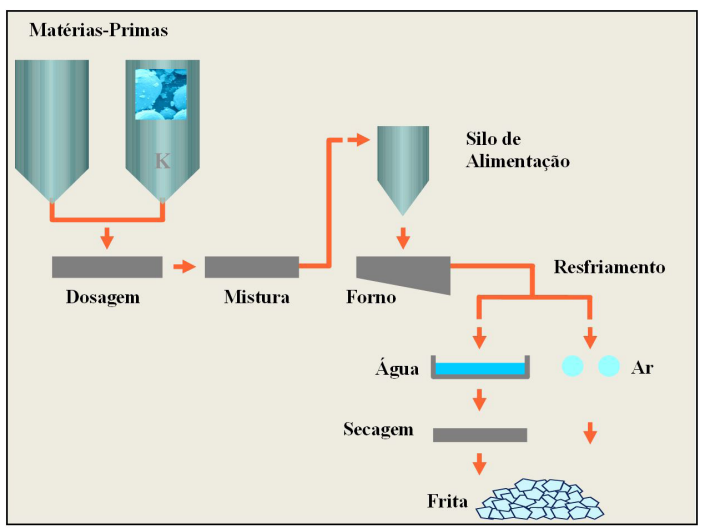

Fonte: extraído de apresentação do Instituto de Tecnologia Cerámica - ITC, Castellon - Espanha (2006).

Figura 4 - Processo de produção de fritas cerâmicas. 
Tabela 2 - Consumo total estimado de matérias-primas minerais pelos colorifícios no Brasil - ano base 2017.

\begin{tabular}{|c|c|c|}
\hline \multicolumn{2}{|c|}{ Matéria-Prima } & Toneladas/ano \\
\hline \multirow{7}{*}{ Naturais } & Quartzo & 167.000 \\
\hline & Feldspato & 128.000 \\
\hline & Argila & 33.000 \\
\hline & Calcário & 27.000 \\
\hline & Caulim & 42.000 \\
\hline & Zircônio & 25.000 \\
\hline & Talco & 8.300 \\
\hline \multirow{6}{*}{ Sintéticas } & Boratos & 22.000 \\
\hline & Óxido de zinco & 11.000 \\
\hline & Nitratos & 2.700 \\
\hline & Vidro & 70.000 \\
\hline & Outros & 14.000 \\
\hline & Total & 550.000 \\
\hline
\end{tabular}

Obs. Outros: carbonatos, minérios de lítio, barrilha, etc.

Fonte: elaborado pelos autores a partir de informações coletadas com especialistas do segmento de colorifícios.

controle rígido das especificações químicas. As principais substâncias minerais utilizadas são quartzo, feldspatos, calcários, caulim, argilas, zircônio e talco. Para esses minerais industriais cerâmicos são requeridos elevada pureza e controle rígido das especificações químicas.

Com base na produção anual de 550 mil toneladas de insumos e a partir das formulações médias para fritas e demais produtos fabricados, é estimado o consumo anual de matérias-primas pelos colorifícios, que se encontra descriminado na Tabela 2.

Entre os segmentos da cadeia produtiva cerâmica, os colorifícios correspondem a um dos elos com maior investimento em inovação, podendo alcançar, entre as empresas líderes, valores da ordem ou superiores a $1 \%$ do faturamento das corporações (Cabral Junior et al., 2010a). Além de designers, as empresas contam com engenheiros e técnicos de nível médio que prestam serviços de assistência técnica e dão assessoria de processo às empresas cerâmicas. Em termos do padrão tecnológico, as maiores empresas brasileiras equiparam-se às grandes empresas estrangeiras. Seus atualizados processos produtivos seguem as tendências internacionais, hoje ditadas principalmente pela Espanha, líder mundial em esmaltação. No entanto, os esforços inovativos no país restringem-se, na maior parte das vezes, a adaptações de produtos e processos às matérias-primas e demais condições locais.

\subsection{Cenário Paulista}

O Estado de São Paulo conta atualmente com cinco dos maiores colorifícios em operação no país. Dispõe ainda de pelos menos outras 10 unidades de processamento, mistura e comercialização de insumos de acabamento de corpos cerâmicos. A retração econômica que prejudicou o setor de revestimento refletiu-se fortemente no segmento, com a paralisação das operações no Estado de outras cinco fábricas de menor porte (ver Tabela 1).
Tabela 3 - Consumo total estimado de matérias-primas minerais pelos colorifícios no Brasil e Estado de São Paulo - ano base 2017.

\begin{tabular}{|clrr}
\hline \multirow{5}{*}{ Matérias-Primas } & \multicolumn{2}{c}{$\begin{array}{c}\text { Consumo }- \\
\text { Toneladas/Ano }\end{array}$} \\
\cline { 2 - 3 } & & Brasil & $\begin{array}{c}\text { São } \\
\text { Paulo }\end{array}$ \\
\hline \multirow{5}{*}{ Naturais } & Quartzo & 167.000 & 117.323 \\
& Feldspato & 128.000 & 89.924 \\
& Argila Plástica & 33.000 & 23.184 \\
& Calcário & 27.000 & 18.968 \\
& Caulim & 42.000 & 29.506 \\
& Zircônio & 25.000 & 17.563 \\
& Talco & 8.300 & 5.831 \\
& Boratos & 22.000 & 15.456 \\
& Óxido de zinco & 11.000 & 7.728 \\
& Nitratos & 2.700 & 1.897 \\
& Vidro & 70.000 & 49.177 \\
& Outros & 14.000 & 9.835 \\
& Total & $\mathbf{5 5 0 . 0 0 0}$ & $\mathbf{3 8 6 . 3 9 2}$
\end{tabular}

Obs. Outros: carbonatos, minérios de lítio, barrilha, etc Fonte: elaborado pelos autores a partir de informações coletadas com especialistas do segmento de colorifícios.

No Polo de Santa Gertrudes, aglomeração produtiva que se consolidou a partir dos anos 1990, observa-se que ultimamente só tem se instalado unidades de misturas (p.ex. Esmalglass e Torrecid), sendo que as plantas com fornos de fusão são relativamente antigas.

A Tabela 3 apresenta o consumo de matérias-primas pelo segmento em São Paulo, que totalizou cerca de 385.000 toneladas em 2017, correspondendo a $70 \%$ do total demandado pelos colorifícios no país ${ }^{4}$.

Somente as matérias-primas naturais (quartzo, feldspato, argila, calcário, caulim, zircônia e talco) somam mais de 300.000 toneladas, o que indica que os colorifícios representam um grande consumidor de algumas variedades especiais de minerais cerâmicos no estado, caso dos feldspatos de primeira qualidade, proveniente de pegmatitos da região Nordeste, argilas plásticas de queima clara, caulim, além de areia silicosa, esta a única substância mineral abundante no território paulista (areias quartzosas lavradas em grandes minas na região de Descalvado e Analândia).

\section{INDÚSTRIA DE SANITÁRIOS}

O segmento cerâmico de Louça Sanitária produz bacias, caixas d'águas, bidês, lavatórios, colunas, mictórios, tanques de lavar roupas e acessórios.

\footnotetext{
${ }^{4}$ A relação de $70 \%$ de consumo de matérias-primas em relação à demanda total no país é indicada pela relação da produção paulista e brasileira de revestimentos cerâmicos, respectivamente, de 555 e 790 milhões de $\mathrm{m}^{2}$. Considerou-se que a produção de insumos dos colorifícios localizados no estado é responsável pelo suprimento de todo o parque cerâmico paulista.
} 
A indústria de sanitários surgiu no Brasil na década de 1920. Até então, toda louça sanitária era importada. Na ocasião, duas empresas cerâmicas distintas se uniram para a formação da Companhia Cerâmica Jundiaiense para a produção de louças sanitárias brancas vitrificadas, e em 1968 foi incorporada à Deca (Grupo Duratex). No final da década de 1940 foi fundada a Cerâmica Colônia, que introduziu a louça sanitária colorida. Em 1958 esta empresa foi adquirida pela multinacional americana Ideal Standard.

$\mathrm{Na}$ década de 1970 houve uma grande expansão desse segmento, com surgimento de novas unidades industriais. Inicialmente concentrada na região Sudeste, a cerâmica de louça sanitária expandiu-se para o Nordeste e, mais timidamente, para o Sul, contando em 2018 com 17 unidades fabris de porte médio a grande (capacidade produtiva em torno de 1 milhão peças/ano ou mais) e pelo menos outras sete de porte pequeno (menos de 200 mil peças/ano).

Diferentemente dos setores de revestimentos e cerâmica vermelha, constituídos por uma estrutura industrial desconcentrada e de capital nacional, o segmento de sanitários é concentrado e conta com importante participação de capital estrangeiro. Atualmente, as empresas nacionais são responsáveis por $60 \%$ da produção no país, sendo que as duas empresas líderes (Roca e Deca) detém mais de $60 \%$ do mercado.

\subsection{Estrutura Produtiva e Empresarial - Contexto Brasileiro}

Em 2016, o Brasil produziu cerca de 22,5 milhões de peças de cerâmica sanitária (Anfacer, 2018) entre bacias com caixa acoplada (39\%), cubas $(24 \%)$, bacia convencional (18\%), lavatório e coluna (10\%), tanques (5\%) e mictórios (4\%). Se considerarmos que toda a produção foi comercializada no país, esse montante correspondeu, ao preço mínimo no varejo, a R\$2,7 bilhões. As poucas referências na evolução da produção nacional podem ser vista na Tabela 4.

As unidades fabris do segmento de sanitários, suas respectivas localizações, capacidade instalada e produção estão relacionadas na Tabela 5, com a regionalização da sua estrutura produtiva ilustrada na Figura 5.

Os estados líderes em capacidade instalada e produção são Minas Gerais, Pernambuco e São Paulo. As regiões Nordeste e Sudeste concentram o parque fabril, respectivamente com $60 \%$ e $36 \%$ da capacidade instalada.

Tabela 4 - Produção brasileira de louça sanitária - triênio 2006 -2008 e 2016.

\begin{tabular}{cc}
\hline Ano & $\begin{array}{c}\text { Produção } \\
\text { Milhões de Peças }\end{array}$ \\
\hline 2006 & 16 \\
2007 & 18 \\
2008 & 21 \\
2016 & 22,5 \\
2017 & 22,8 \\
\hline
\end{tabular}

Fonte: Cabral Junior et al. (2010) e Anfacer (2018)
Completando a estrutura de produção, o Rio Grande do Sul, com uma planta industrial operando, dispõe de cerca de $4 \%$ da capacidade instalada no país.

A produção de louça sanitária em 2017 superou em pouco mais de $1 \%$ a de 2016 , alcançando 22,8 milhões peças, correspondendo a uma ociosidade de $33 \%$ do parque industrial. Dentre o universo de produtores, a Deca, maior empresa nacional, possui plantas em Jundiaí - SP, São Leopoldo - RS (atualmente paralisada), Nova Iguaçu RJ, Cabo de Santo Agostinho - PE e João Pessoa- PB. O Grupo Roca, de origem espanhola, detém as marcas Roca, Incepa, Logasa e Celite, com fábricas em Jundiaí SP, Serra - ES, Recife - PE e Santa Luzia- MG. As demais fábricas são de grupos ou empresas familiares brasileiras, exceto a Kolher/Fiori, de capital americano, que reduziu temporariamente a produção em 2019.

As informações disponíveis, bem como as apreciações coletadas com empresas líderes e profissionais do setor, indicam que a produção da indústria brasileira deva se situar entre as maiores no mundo, nas quais devem participar, além do Brasil, países como China, México, Turquia, Bulgária e Rússia. O Brasil detém também um consumo expressivo de louças sanitárias, que o coloca entre os principais mercados mundiais como China, EUA, Índia, Japão, Rússia, Espanha, entre outros.

O mercado interno consome a maior parte da produção brasileira e está plenamente atendido com os produtos convencionais e de maior luxo. Estima-se que o mercado doméstico absorvia $80 \%$ do total produzido na primeira década dos anos 2000. Posteriormente, as exportações foram bastante afetadas, primeiro pela crise imobiliária nos EUA e, em seguida, pela contaminação da economia mundial,

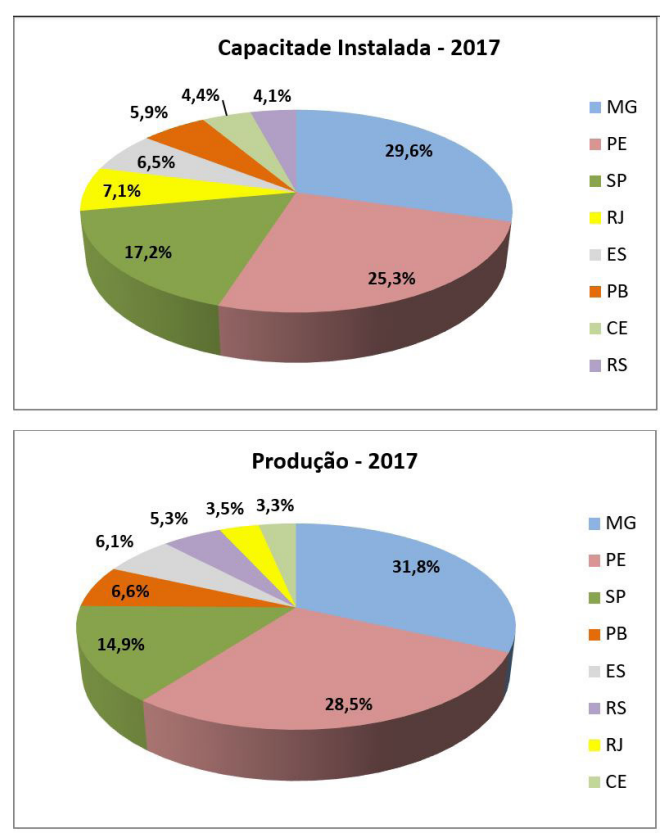

Fonte: elaborado pelos autores.

Figura 5 - Regionalização da capacidade instalada e produção da indústria de sanitários - ano base 2017. 
Tabela 5 - Relação das unidades industriais de louça sanitária, localização e estimativa da capacidade instalada e produção no Brasil - ano base 2017.

\begin{tabular}{|c|c|c|c|c|c|c|}
\hline $\begin{array}{l}\text { EMPRESA / } \\
\text { GRUPO }\end{array}$ & & UNIDADES & LOCALIDADE & UF & $\begin{array}{l}\text { CAPACIDADE } \\
\text { ANUAL } \\
\text { INSTALADA } \\
\text { MIL PEÇAS } \\
\end{array}$ & $\begin{array}{c}\text { PRODUÇÃO } \\
2017 \\
\text { MIL PEÇAS }\end{array}$ \\
\hline \multirow{5}{*}{ DURATEX S.A } & 1 & DECA Louças - PB & João Pessoa & PB & 2.000 & 1.500 \\
\hline & 2 & DECA Louças - PE & Cabo Sto Agostinho & PE & 2.800 & 1.800 \\
\hline & 3 & DECA Louças - RJ & Queimados & RJ & 2.400 & 800 \\
\hline & 4 & DECA Louças - RS* & São Leopoldo & RS & 1.400 & 1.200 \\
\hline & 5 & DECA Louças - SP & Jundiaí & SP & 3.000 & 1.500 \\
\hline \multirow{4}{*}{ ROCA BRASIL } & 6 & CELITE - MG & Santa Luzia & MG & 4.200 & 2.400 \\
\hline & 7 & LOGASA & Serra & ES & 2.200 & 1.400 \\
\hline & 8 & CELITE - PE & Recife & PE & 2.200 & 2.200 \\
\hline & 9 & INCEPA & Jundiaí & SP & 1.430 & 850 \\
\hline ETERNIT & 10 & $\begin{array}{l}\text { CSC - Cia Sulam de } \\
\text { Cerâmica }\end{array}$ & Caucaia & $\mathrm{CE}$ & 1.500 & 750 \\
\hline KOHLER & 11 & Fiori/ Kohler & Andradas & MG & 1.700 & 1.700 \\
\hline HERVY & 12 & $\begin{array}{l}\text { Cerâmica Ind. de } \\
\text { Taubaté }\end{array}$ & Taubaté & SP & 950 & 600 \\
\hline ICASA & 13 & $\begin{array}{l}\text { Ind. Cerâm. Andradense } \\
\text { - ICASA }\end{array}$ & Andradas & MG & 2.400 & 2.100 \\
\hline LORENZETTI & 14 & Lorenzetti Louças & Poços de Caldas & MG & 1.400 & 700 \\
\hline LUZARTE & 15 & Luzarte Estrela & Caruaru & $\mathrm{PE}$ & 2.400 & 1500 \\
\hline MARI & 16 & Mari Louças Sanitárias & São Caetano & $\mathrm{PE}$ & 1.200 & 1.000 \\
\hline ONIX & 17 & Onix Louças Sanitárias & Uberaba & MG & 120 & 120 \\
\hline SANTA CLARA & 18 & Louças Sanit. Sta Clara & Araxá & MG & 150 & 150 \\
\hline $\begin{array}{l}\text { CASA } \\
\text { SANTAMARINA }\end{array}$ & 19 & $\begin{array}{l}\text { Casa Santamarina } \\
\text { Louças Sanitárias }\end{array}$ & Perdizes & MG & 100 & 100 \\
\hline ZETA & 20 & Zeta & Itupeva & SP & 120 & 120 \\
\hline MGA & 21 & MGA & Itupeva & SP & 140 & 140 \\
\hline MELATE (ASTRA) & 22 & Melate/Japi/ & Itupeva & SP & 100 & 100 \\
\hline MONDIALLE & 23 & Mondialle & Santa Barbara do Oeste & SP & 100 & 100 \\
\hline TOTAL & & & & & 34.010 & 22.830 \\
\hline
\end{tabular}

Obs.: * Atualmente paralisada.

Fonte: elaborado pelos autores a partir de informações coletadas em pesquisa de campo e criticadas por especialistas do setor de louça sanitária.

caindo de um patamar histórico de 20\% para menos de $10 \%$ da produção nacional (Cabral Junior et. al., 2010b). Essa queda reflete-se até os dias de hoje, sendo que apenas a empresa Kohler, situada em Poços de Caldas- MG, de capital americano, apresenta um forte percentual de exportação para o próprio grupo nos Estados Unidos. No entanto, com a desvalorização do real frente ao dólar, alguns especialistas do setor acreditam na retomada das exportações, aproveitando-se da capacidade ociosa do parque fabril.

Os preços relativamente baixos das louças sanitárias no mercado internacional, mormente para as peças mais comuns, constituem uma forte barreira à entrada de produtos importados. Outro fator que inibe a importação, mas limita também a exportação, é o grande volume das peças e o baixo peso das mesmas nos contêineres dos navios.

Quanto à comercialização dos produtos, há uma grande variação de preços em função dos tipos de louças, e da qualidade e sofisticação dos produtos, com peças mais simples, populares, na faixa de R $\$ 100,00$ ou menos (bacias convencionais, cubas, lavatórios, colunas), até conjuntos sofisticados, tecnicamente e em seu design, que podem alcançar valores superiores a $\mathrm{R} \$ 2.000,00$. Informações mais detalhadas, com faixas de preço por tipos de produtos, são fornecidas na Tabela 6.

Fato importante verificado nos últimos anos foi o surgimento de novas empresas dentro desse setor eminentemente concentrado, a maioria de pequeno porte e fabricante de peças populares, no Nordeste, sul de Minas Gerais e na região de Jundiaí- SP. Apesar da pequena fatia do mercado interno conquistado por esses novos empreendimentos, trata-se de uma movimentação empresarial significativa em busca de oportunidades relacionadas às camadas de renda relativamente mais baixas. Contudo, diante da demanda atual reprimida, detectou-se que parte dessas empresas 
Tabela 6 - Preços de louças sanitárias comercializadas no mercado brasileiro.

\begin{tabular}{lcccc}
\hline \multicolumn{1}{c}{ Louça } & $\begin{array}{c}\text { Faixa } \\
\text { Intermediária } \\
\text { R\$ }\end{array}$ & $\begin{array}{c}\text { Faixa Luxo } \\
\text { R\$ }\end{array}$ & $\begin{array}{c}\text { Faixa Popular } \\
\text { R\$ }\end{array}$ & $\begin{array}{c}\text { Participação } \\
\text { Mercado } \\
\text { (Quantidade) }\end{array}$ \\
\hline Bacia com Box (caixa acoplada) & $350-700$ & $>3.000$ & 165 & $39 \%$ \\
Bacia convencional (com válvula) & $250-350$ & $>2.000$ & 90 & $18 \%$ \\
Lavatório e Coluna & $150-300$ & $>500$ & 100 & $10 \%$ \\
Cuba & $200-300$ & $>2.000$ & 57 & $24 \%$ \\
Tanque & 280 & 350 & 215 & $5 \%$ \\
Mictório & 700 & $>2.000$ & 195 & $4 \%$ \\
$*$ Faixa de valores & & &
\end{tabular}

* Faixa de valores mais frequente praticados no comércio varejista.

Fonte: elaborado pelos autores a partir de informações coletadas em pesquisa de campo e criticadas por especialistas do setor de louça sanitária.

Tabela 7 - Indústrias de louça sanitária no Estado de São Paulo.

\begin{tabular}{llccc}
\hline \multicolumn{1}{c}{ GRUPO } & \multicolumn{1}{c}{$\begin{array}{c}\text { EMPRESAS E SUAS } \\
\text { UNIDADES }\end{array}$} & LOCALIDADE & $\begin{array}{c}\text { CAPACIDADE } \\
\text { ANUAL } \\
\text { INSTALADA } \\
\text { MIL PEÇAS }\end{array}$ & $\begin{array}{c}\text { PRODUÇÃO } \\
\text { MIL PEÇAS }\end{array}$ \\
\hline DECA & \multicolumn{1}{c}{$\begin{array}{c}\mathbf{2 0 1 7} \\
\text { Deca Louças - SP - Fábrica } \\
\text { Louças Jundiaí I }\end{array}$} & Jundiaí & 3.000 & 1.500 \\
HERVY & Incepa & Jundiaí & 1.430 & 850 \\
Zeta & Cerâmica Industrial de Taubaté & Taubaté & 950,00 & 600 \\
MGA & Zeta & Itupeva & 120,00 & 120 \\
Melate (Astra) & MGA & Itupeva & 140,00 & 140 \\
Mondialle & Mondialle & Itupeva & 100,00 & 100 \\
TOTAL ESTIMADi & & Sta. Bárbara do Oeste & 100,00 & 100 \\
\hline
\end{tabular}

Fonte: elaborado pelos autores.

encontra-se em dificuldade e estão buscando parcerias e, até mesmo, a sua venda para as empresas maiores e mais estruturadas.

\subsection{Cenário Paulista}

Foi no território paulista que se iniciou a implantação da indústria de louça sanitária no país, onde se consolidou, em Jundiaí, o primeiro importante polo produtor nacional, com a maior planta industrial da Deca e importante fábrica do Grupo Roca. Adicionalmente, pequenas empresas vêm se instalando na região, contando-se atualmente com sete plantas industriais no Estado (Tabela 7).

A indústria paulista de sanitários operou em 2017 com uma capacidade ociosa de $40 \%$, resultando em uma produção de 3,4 milhões de peças, o que representou $15 \%$ do total de peças fabricadas no país.

\subsubsection{Processo produtivo}

Em termos de configuração, as plantas industriais de maior porte e mais estruturadas são compostas, basicamente, de três segmentos: unidade de beneficiamento de matérias-primas minerais e composição de massa, setor de fundição (conformação das peças cerâmicas), e queima realizada em fornos túneis de queima contínua. Predominam instalações com fornos à gás natural $(\mathrm{GN})$ de seção baixa. As pequenas fábricas trabalham com fornos intermitentes, produzindo pouca variedade de peças.

De forma geral, o setor produtivo, liderado pelas maiores empresas, tem buscado o aprimoramento constante, em termos de tecnologia em equipamentos, processo e produtos. Motivadas pelo Programa Brasileiro de Qualidade e Produtividade no Habitat (PBQP-H), a maior parte das empresas possui certificação de produto e processo. Trata-se de um segmento industrial dominado por tecnologias maduras, sendo que as maiores empresas brasileiras rivalizam-se com as empresas líderes estrangeiras (europeias, asiáticas e norte-americanas). A Figura 6 ilustra de forma simplificada o processo produtivo de sanitários, desde a entrada das matérias-primas até o produto final.

\subsubsection{Sistema de suprimento mineral}

A cerâmica de sanitários utiliza na composição da massa matérias-primas plásticas e matérias-primas "duras", não plásticas. De modo geral, as matérias-primas plásticas são desagregadas em água e peneiradas, e as não plásticas são moídas a seco, até atingir a granulometria adequada. Em seguida, esses materiais são misturados em tanques com agitação mecânica, nos quais se adicionam reagentes químicos (por exemplo, silicato de sódio) para corrigir as propriedades da suspensão. A polpa assim obtida 


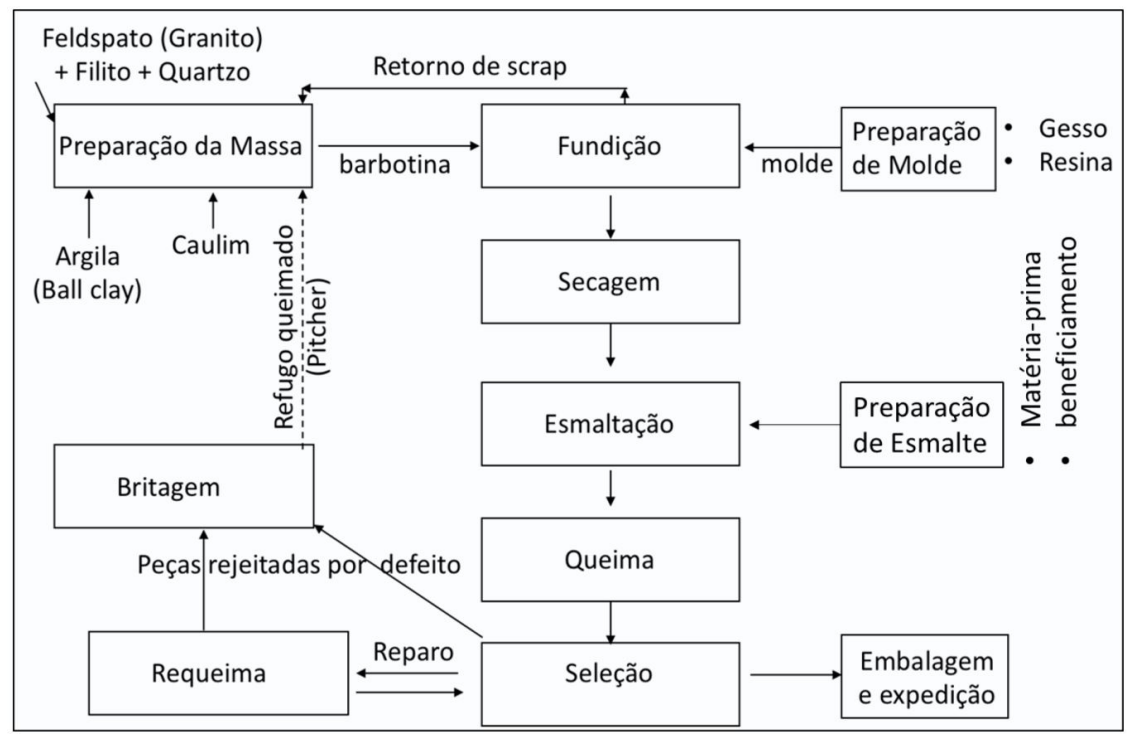

Fonte: modificado de ABCeram (2018).

Figura 6 - Fluxograma do processo de fabricação de sanitários.

Tabela 8 - Tipos e consumo estimado de matérias-primas minerais para massa de louça sanitária na indústria paulista - ano base 2017.

\begin{tabular}{lccc}
\hline \multicolumn{1}{c}{ MATÉRIA-PRIMA } & $\mathbf{0}$ & Toneladas/Ano & $\begin{array}{c}\text { Preço Médio(CIF) } \\
\text { R\$/t }\end{array}$ \\
\hline Argilas Plásticas (ball clays) & $20-30$ & 20.000 & 350 \\
Caulim & $6-8$ & 5.800 & 180 \\
Leucofilito & 12 & 12.000 & 80 \\
Rochas Feldspáticas (granitóides e feldspato) & $32-40$ & 30.000 & 50 \\
Quartzo & 3 & 2.400 & 40 \\
Refugo queimado (pitcher) & 5 & 3.600 & \\
TOTAL & 5 & $\mathbf{7 4 . 0 0 0}$ & $\mathbf{1 4 0}$
\end{tabular}

Obs.: considerado uma formulação média para louças sanitárias, que pode variar em função da disponibilidade regional de matérias-primas.

Fonte: elaborado pelos autores.

(barbotina), após peneiramento, é bombeada para o setor de fundição, onde é feita a colagem das peças sanitárias em moldes de gesso ou em moldes de resina, por pressão.

As principais matérias-primas minerais usadas compreendem argila, caulim e fundentes. Os fundentes, originalmente compostos por feldspatos puros, foram substituídos por fundentes mais baratos, tais como rochas feldspáticas (pegmatito e granito) e leucofilito. O substituto mais comum na região de Jundiaí é o pedrisco

${ }^{5}$ Uma das principais perdas para as fábricas são as peças reprovadas após a queima, sem possibilidades de reparo, cujos materiais podem ser denominados de refugos queimados, pitcher ou cacos. Essas perdas podem variar de $5 \%$ a $10 \%$ nas plantas paulistas. Há pouco mais de uma década, esses materiais constituíam resíduos inertes que eram destinados basicamente a aterros. Hoje, praticamente todo material é cominuídos e reincorporado à massa cerâmica. de granito, coproduto de mineração de brita no município (Mineração Tavares Pinheiro). Este material é a principal matéria-prima feldspática comercializada tanto na forma bruta, ou concentrada e deferrizada (planta em Itupeva- SP). A Tabela 8 apresenta a composição média das massas, estimativa do consumo anual de matérias-primas e preços médios praticados (CIF).

Em 2017, o setor de sanitários consumiu cerca 74.000 toneladas de minerais industriais cerâmicos (incluindo chamote de caco). Observa-se que o setor operou com grande ociosidade nesses últimos três anos em um cenário de demanda reprimida. A expectativa de retorno da produção em níveis compatíveis com a normalização do mercado doméstico e a possibilidade de exportações pode elevar substancialmente o patamar de consumo de insumos minerais.

Em função do maior valor unitário, as argilas são as matérias-primas de maior custo na massa. Tratam-se de argilas plásticas cauliníticas de queima clara, conhecidas 
classicamente como ball clays, que exercem funções específicas no processo de fabricação de louças sanitárias, destacadas a seguir:

- capacidade de dispersão e concentração de sólidos na suspensão (barbotina), que permite fluidez, bombeamento e enchimento dos moldes;

- facilidade e rapidez de formação de parede da barbotina no molde, que confere produtividade ao processo de moldagem das peças;

- aporte de resistência mecânica à peça verde, que evita a deformação das peças durante a secagem e manuseio; e

- cor clara de queima.

Para aportar essas características técnicas, as argilas tipo ball clay devem possuir um conjunto de propriedades específicas, tais como alta plasticidade, certo conteúdo de matéria orgânica, distribuição granulométrica específica, capacidade de troca catiônica especial, baixo conteúdo de óxidos cromóforos, como $\mathrm{Fe}_{2} \mathrm{O}_{3}$, e baixo conteúdo de sais solúveis.

Em razão de suas propriedades especiais, as ocorrências dessas argilas são escassas no país, sendo que aquelas mais adequadas ao processo de fabricação de louças sanitárias localizam-se em São Simão- SP e arredores de Recife- PE, ambas com dificuldades de produção ${ }^{6}$. Para minimizar o consumo desses minérios mais nobres e caros, argilas provenientes de outros depósitos são agregadas adicionalmente nas massas. Dentre essas argilas "de apoio", destacam-se jazidas no Paraná e Minas Gerais. Em razão da escassez e custo de transporte, essas argilas também possuem valores relativamente elevados.

O caulim constitui a segunda matéria-prima de maior valor unitário. Geralmente após a lavra, passam por processo de beneficiamento a úmido, com separação da areia, filtro prensagem e secagem, que aumenta os custos de produção e valor de aquisição para os fabricantes. No entanto, essa substância tem uso percentual menor na composição da massa, não influenciando tanto no custo final. O caulim geralmente está associado a corpos de rochas pegmatíticas, constituindo depósitos de pequeno porte, como é o caso das ocorrências na região do Embu Guaçu (SP). Outros fornecedores são de Minas Gerais e Paraná.

Tendo em vista o elevado valor dos componentes plásticos, tem havido interesse de produtores especializados internacionais em se estabelecer no mercado doméstico, como os grupos Sibelco e Imerys, produzindo misturas balanceadas de argilas e caulins em centrais de produção de massa. ${ }^{7}$

A matéria-prima que tem maior peso percentual na massa e, portanto, grande influência na formação de

\footnotetext{
${ }^{6}$ Entre os fatores que dificultam a produção de argilas plásticas destaca-se: no caso paulista, as poucas jazidas conhecidas são de pequeno porte, com reservas restritas e de distribuição errática e, em Pernambuco, os principais depósitos estão situados em áreas com restrições ambientais e alta valorização imobiliária.

${ }^{7}$ O Grupo Imerys conta com uma planta em Rio Claro (SP) e a Sibelco com uma unidade desativada em Ipojuca (PE).
}

preço, é o feldspato, o qual é aportado a partir de rochas feldspáticas, geralmente granitoides leucocráticos (baixo teor de ferro). Comercialmente, o produto mais tradicional no mercado é o granito Tavares Pinheiro, de Jundiaí-SP, que, além de fornecer a fundência exigida nas queima, situa-se próximo ao centro consumidor e tem escala de produção, pois é um coproduto de uma pedreira de brita. No entanto, à expansão desta mina encontra-se limitada na fácies leucocrática desse maciço granítico (porção da rocha com baixa conteúdo de ferro), que é o litotipo mais adequado à indústria de louça sanitária. Em decorrência da limitação futura desse tradicional fornecedor, outras opções de rochas feldspáticas já vêm sendo utilizadas ou encontram-se em etapa de estudo, como o granito da Pedreira São Jerônimo em Itupeva e o feldspato de Salto de Pirapora.

A outra matéria-prima que compõe a massa das louças sanitárias é o filito, rocha mista de plasticidade e fundência, introduzida ainda no início do desenvolvimento dessa indústria no Brasil, em meados do século passado. $\mathrm{O}$ filito substituiu parcialmente o feldspato, barateando a massa, sobretudo no processo de moagem. Nas indústrias paulistas, o filito contribui com $12 \%$ da massa e é proveniente de Itapeva-SP e de Minas Gerais (região de Arcos e Ouro Preto).

Para a produção dos esmaltes ou vidrados utilizam-se matérias-primas naturais (feldspato, quartzo, caulim, calcita) e sintéticas (bórax, ácido bórico, carbonato de sódio, nitrato de sódio, óxidos de chumbo, óxido de zinco, entre outras). Os esmaltes são aplicados à superfície dos corpos cerâmicos e após queima, formam uma camada vítrea, delgada e contínua. As finalidades desses vidrados são aprimorar a estética, tornar o produto impermeável e melhorar a resistência mecânica. Essas matérias-primas são beneficiadas ou processadas artificialmente com alto controle de qualidade, sendo fornecidas por colorifícios, empresas químicas ou moageiras, essas últimas apenas no caso da cominuição de substâncias naturais.

De forma geral, constata-se que há deficiências em termos de qualidade e custo no abastecimento de algumas matérias-primas, o que pode seguir interferindo na competitividade dessa indústria. Com o reaquecimento da economia, as adversidades no suprimento mineral tendem a se agravar pela escassez de matérias-primas, sobretudo no caso de argilas plásticas de queima clara.

\section{INDÚSTRIA DE ISOLADORES ELÉTRICOS}

A cerâmica técnica tradicional engloba porcelana elétrica (isoladores e peças para componentes eletroeletrônicos) e porcelana técnica. ${ }^{8}$ Aqui são tratados apenas os isoladores, que se constituem um dos principais produtos da cerâmica técnica tradicional.

\footnotetext{
${ }^{8} \mathrm{O}$ segmento de porcelana técnica compreende uma série de produtos aplicados em situações sujeitas a amplas variações de temperatura, obtidos por diferentes matérias-primas e processos, para finalidades diversas, tais como: química, eletroeletrônica, térmica, mecânica, óptica, magnética e nuclear.
} 
Os isoladores elétricos são dispositivos utilizados para garantir o isolamento de fios ou cabos energizados, apresentando grande capacidade de se opor à passagem de corrente elétrica (alta resistividade), além de elevada resistência mecânica.

\subsection{Estrutura Produtiva e Empresarial}

A primeira indústria no Brasil teve origem a partir de uma fábrica de porcelanas decorativas para uso doméstico na cidade de Pedreira (SP). Em 1943, com as dificuldades geradas ao comércio internacional durante a II Guerra Mundial e com o foco na substituição de importações, iniciou-se, pela Cerâmica Santana, a produção de isoladores elétricos no país. Outras empresas foram surgindo nas décadas subsequentes, fomentadas pela grande expansão do parque energético nacional, com a construção de grandes hidroelétricas.

Desde então, a produção de isoladores concentrou-se nessa cidade do interior paulista, que conta atualmente com três empresas: Cerâmica Santa Terezinha S/A, Electro Vidro S/A (antiga Cerâmica Santana - PCC Insulators) e Cerâmica São José Ltda.

Os dados disponíveis sobre a produção no país datam da década passada. Como a estrutura do parque produtivo mantêm-se praticamente as mesmas, estima-se que a produção anual de isoladores elétricos situa-se entre 25.000 a 35.000 toneladas de cerâmica queimada.

\subsection{Processo Produtivo}

A produção das peças inicia-se com a mistura das matérias-primas, seguida de processo de moagem com água em moinho de bola, promovendo-se a cominuição e a homogeneização da massa. A partir de então, os produtos podem ser conformados a seco ou por massa plástica.

A massa plástica é obtida por meio da passagem da barbotina (suspensão proveniente do moinho de bolas) por processo de filtro-prensagem. Em seguida, a mistura passa por uma extrusora com câmara de vácuo, para compactação em forma cilíndrica, Para a conformação das peças são utilizadas duas rotas, por prensagem ou tornearia. Pelo processo de prensagem, os cilindros são segmentados em tamanhos adequados e são prensados no estado plástico. $\mathrm{Na}$ rota por tornearia, os cilindros (inteiros ou segmentados) são submetidos a um estágio mais rigoroso de secagem, de forma a garantir uma elevada resistência mecânica, permitindo o torneamento de peças até grandes dimensões, o que depende, dentre outros componentes da massa, de uma argila qualificada.

No caso de prensagem isostática (conformação a seco), a barbotina é seca em spray dryer e depositada em moldes em câmeras de alta pressão. Esse método vem sendo utilizado mais recentemente em algumas indústrias.

Após a conformação, a secagem é concluída, sendo que as peças mais úmidas ainda passam por estufa. Em seguida, recebem uma camada de esmalte com a finalidade de proteção e impermeabilização da superfície e potencialização de suas propriedades mecânicas e elétricas. Os produtos são sinterizados em temperaturas entre $1.200^{\circ} \mathrm{C}$ e $1.400{ }^{\circ} \mathrm{C}$, sendo então finalizados com a adição de ferragens, quando necessário, e testados mecânica e eletricamente. A Figura 7 apresenta de forma mais detalhada as etapas e variantes do processo produtivo.

\subsection{Sistema de Suprimento Mineral}

Os isoladores elétricos são constituídos de matérias-primas plásticas e não plásticas, conformadas por processos úmidos e plásticos. Para atender as especificações técnicas, sobretudo as propriedades elétricas e mecânicas, a composição da massa deve ter baixo teor de $\mathrm{Fe}_{2} \mathrm{O}_{3}$, proporcionar alta resistência mecânica das peças, a seco e queimadas, além de controlar outros parâmetros importantes, como retração de secagem e queima, deformações piroplásticas, afora os problemas comuns de secagem e queima (trincas, empenamentos, etc.).

Os produtos são de composição de porcelana triaxial (quartzo, feldspato e caulinita), incluindo ainda produtos inertes para controle de retração e aumentar a resistência mecânica. Para a elevação da resistência mecânica, o quartzo pode ser substituído, total ou parcialmente, por sínter de argila aluminosa ou alumina. As principais substâncias minerais utilizadas são argila plástica, caulim, feldspato, talco e quartzo.

Para utilização em isoladores de baixa tensão empregam-se, geralmente, composições de porcelanas ricas em quartzo (silicosas), com a quantidade de argila caulinítica e caulim variando entre $40 \%$ e $60 \%$, feldspato entre $20 \%$ e $35 \%$ e quartzo entre $20 \%$ e $30 \%$.

As porcelanas que incorporam alumina, por possuírem propriedades dielétricas adequadas e propriedades

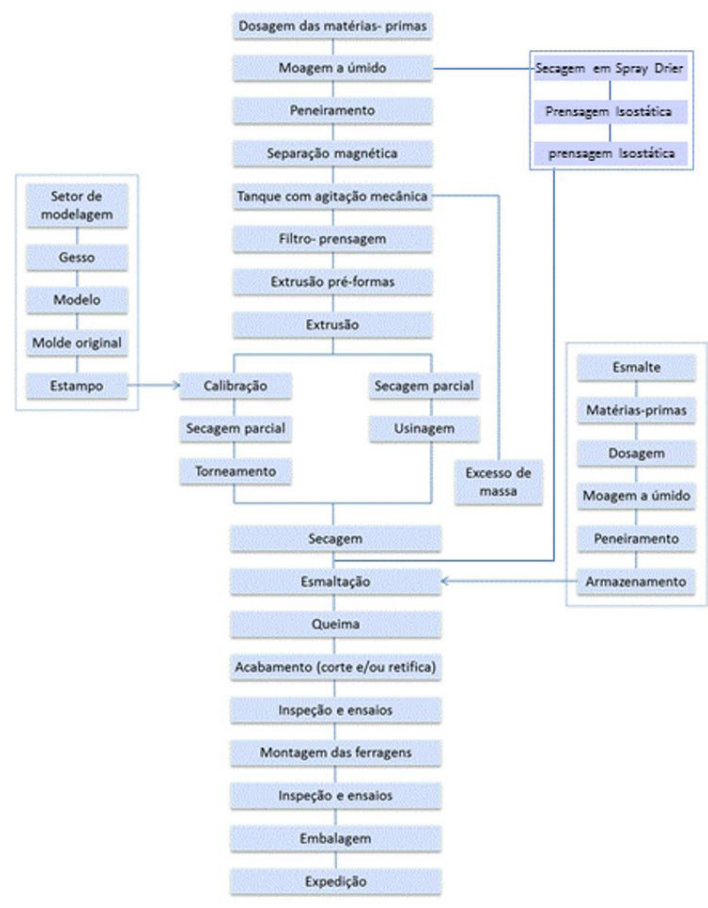

Fonte: São Paulo, 1992, modificado.

Figura 7 - Fluxograma típico do processo produtivo de isoladores elétricos. 
Tabela 9 - Consumo de matérias-primas minerais pela indústria de isoladores elétricos no Estado de São Paulo - ano base 2017.

\begin{tabular}{lcc}
\hline MATÉRIA-PRIMA & $\mathbf{\%}$ & $\begin{array}{c}\text { Toneladas/ } \\
\text { Ano }\end{array}$ \\
\hline Argilas Plásticas & 25 & 7.500 \\
Caulim & 20 & 6.000 \\
Feldspato & 30 & 9.000 \\
Quartzo & 20 & 6.000 \\
Talco & 5 & 1.500 \\
TOTAL & $\mathbf{1 0 0}$ & $\mathbf{3 0 . 0 0 0}$ \\
\hline
\end{tabular}

Fonte: elaborado pelos autores.

mecânicas superiores às das porcelanas que utilizam quartzo, são utilizadas especialmente na fabricação de isoladores elétricos de alta tensão.

A presença de impurezas, a temperatura, o tempo e a atmosfera de sinterização influenciam fortemente as reações químicas e o desenvolvimento microestrutural da porcelana. Dessa maneira, é necessário o entendimento da relação entre essas variáveis para desenvolver produtos de baixo custo e com propriedades mecânicas e dielétricas adequadas às suas aplicações. Nesse caso, como um dos principais componentes plásticos das massas, destaca-se a elevada qualidade das argilas provenientes da região de Oeiras no Piauí, tradicionalmente usadas pelas indústrias de isoladores.

A Tabela 9 apresenta o consumo de matérias-primas naturais pelas indústrias de isoladores elétricos.

Em função das escassas informações disponíveis sobre a produção de isoladores e a variação na composição de suas massas, essa estimativa deve ser vista com reservas, com os valores indicados sendo entendidos como ordens de grandeza. A quantidade total de matérias-primas consumida anualmente deve alcançar cerca de 30.000 toneladas.

\section{AGRADECIMENTOS}

Os autores expressam seus agradecimentos ao Instituto de Pesquisas Tecnológicas do Estado de São Paulo e a Subsecretaria de Mineração da Secretaria de Energia e Mineração - SEM do Estado de São Paulo (atualmente integrada às funções da Secretaria Estadual de Infraestrutura e Meio Ambiente - SIMA) pelo suporte e financiamento do projeto "Estudo estratégico da cadeia produtiva da indústria cerâmica no Estado de São Paulo - Fase 1", que gerou os resultados apresentados neste artigo.

\section{REFERÊNCIAS}

ABCERAM - ASSOCIAÇÃO BRASILEIRA DE CERÂMICA - Anuário Brasileiro de Cerâmica, 2001.

ABCERAM - ASSOCIAÇÃO BRASILEIRA DE CERÂMICA. Informações gerais na homepage. Disponível em: $<$ http:// www.abceram.org.br>. Acesso em: 03 de abr. 2018.

ANFACER - ASSOCIAÇÃO NACIONAL DOS FABRICANTES DE CERÂMICA DE REVESTIMENTOS, LOUÇAS SANITÁRIAS E CONGÊNERES. Informações gerais na homepage. Disponível em: <http://www.abceram.org.br>. Acesso em: 05 de abr. 2018.

BOSCHI, A. O. Minerais Cerâmicos. Rio de Janeiro: CETEM. Palestra apresentada na Oficina - Minerais Industriais para elaboração da publicação Tendências Tecnológicas Brasil 2015, 2005.

CABRAL JUNIOR, M.; BOSCHI, A.; FERREIRA, A. L. B.; COELHO, J. M. A indústria de colorifícios no Brasil: situação atual e perspectivas futuras. Cerâmica Industrial, v. 15, p. 13-18, 2010a.

CABRAL JUNIOR, M.; TANNO, L. C.; MOTTA, J. F. M.; RUIZ, M. S.; COELHO, J. M. Panorama da indústria cerâmica de sanitários no Brasil. Cerâmica Industrial (Impresso), v. 15, p. 12-18, 2010 b.

CABRAL JUNIOR, M.; AZEVEDO, P. B. M. de; CUCHIERATO, G.; MOTTA, J. F. M. Estudo Estratégico da Cadeia Produtiva da Indústria Cerâmica no Estado de São Paulo: Parte I Introdução e a Indústria de Cerâmica Vermelha. Cerâmica Industrial, v. 24, n. 1, p. 20 - 34, 2019a.

CABRAL JUNIOR, M.; AZEVEDO, P. B. M. de; CUCHIERATO, G.; MOTTA, J. F. M. Estudo Estratégico da Cadeia Produtiva da Indústria Cerâmica no Estado de São Paulo: Parte II Indústria de Revestimentos. Cerâmica Industrial, v. 24, n. 2 , p. $13-21,2019$ b.

COELHO, J. M.; BOSCHI, A.O. Perfil de colorifícios. Produto 43. Cadeia de Colorifícios. RT 70. MME- SGM/ BANCO MUNDIAL. Projeto Estal. Brasília 2009.

IPT - INSTITUTO DE PESQUISAS TECNOLÓGICAS DO ESTADO DE SÃO PAULO. Estudo estratégico da cadeia produtiva da indústria cerâmica no Estado de São Paulo - Fase 1. São Paulo: IPT, 2018. (Rel. n. 153900-205).

ITC - INSTITUTO DE TECNOLOGIA CERÂMICA, Castellon - Espanha (2006).

SÃO PAULO. Secretaria de Estado da Fazenda. (1992). Cerâmica: manual de conhecimentos. São Paulo. 57 p. 